Genij Ortopedii. 2021. Vol. 27, no. 6. P. 686-692.

Original article
https://doi.org/10.18019/1028-4427-2021-27-6-686-692

\title{
Clinical characteristics and factors influencing waiting time to surgery and length of stay in elderly patients
} with hip fractures

\author{
Nam H. Nguyen ${ }^{1}$, Le H. Nguyen ${ }^{1}$, Khoa V. Vu' ${ }^{2}$ Chinh D. Duong ${ }^{3}$, Loi B. Cao ${ }^{4}$, Anh T. Le ${ }^{5 \bowtie}$ \\ ${ }^{1}$ Nghe An Orthopaedic \& Trauma Hospital, Nghe An, Vietnam \\ ${ }^{2}$ Institute of Orthopaedic \& Trauma Surgery, Viet Duc Hospital, Ha Noi, Vietnam \\ ${ }^{3}$ Nghe An Department of Health, Nghe An, Vietnam \\ ${ }^{4}$ National Institute of Malaria, Parasitology and Entomology, Ha Noi, Vietnam \\ ${ }^{5}$ Vietnam Military Medical University, Ha Noi, Vietnam \\ Corresponding author: Le T. Anh, anh_lt@vmmu.edu.vn \\ Abstract
}

Introduction To investigate clinical, laboratory findings and identify pre-operative variables associated with increased waiting time to surgery (WTS) and length of hospital stay (LOS) among hip fracture patients. Material and methods This prospective study is conducted between April 2020 and April 2021. Patients' information was collected from medical records and subjected to analysis using a univariate and multivariate model. Results The study included 118 patients in a mean age of 79.5 years, and the majority were female (68.6 \%). Overall, $66.9 \%$ of the patients had at least one comorbidity. Almost all (95.8 \%) patients had fractures due to a lowimpact fall and an intertrochanteric fracture was the predominant type (61.9\%). The most abnormal laboratory findings at admission were elevated C-reactive protein (CRP) levels (94.9\%) followed by decreased mineral density (85.1 \%), anaemia (81.4 \%), electrolyte abnormalities (69.4\%) and hypoalbuminemia (66.1\%). The mean of WTS among 115 patients undergoing surgical treatment was $52.1 \pm 47$ hours and no patient-related factors had a significant influence on WTS. The mean hospital LOS was $15.9 \pm 4.7$ days. Marked elevation of CRP level $(\mathrm{OR}=3.317, \mathrm{p}=0.042)$, type of surgery $(\mathrm{OR}=4.413, \mathrm{p}=0.005)$ and $\mathrm{WTS}(\mathrm{OR}=4.602, \mathrm{p}=0.001)$ were independent predictors of prolonged LOS. Conclusion Most patients with hip fractures are elderly and suffer from many comorbidities and laboratory abnormalities. No patient-related factors are predictors of WTS but the elevation of CRP, type of surgery and time of waiting to surgery influence the LOS.

Keywords: hip fracture, waiting time to surgery, length of hospital stay, Vietnam

For citation: Nguyen Nam H., Nguyen Le H., Vu Khoa V., Duong Chinh D., Cao Loi B., Le Anh T. Clinical characteristics and factors influencing waiting time to surgery and length of stay in elderly patients with hip fractures. Genij Ortopedii, 2021, vol. 27, no 6, pp. 686-692. https://doi. org/10.18019/1028-4427-2021-27-6-686-692.

\section{INTRODUCTION}

Hip fracture, a break of the upper portion of the femur, is a common injury among the elderly and affects about $18 \%$ of women and $6 \%$ of men globally [1]. As a result of an increased life expectancy and growth of population in the world, cases of hip fractures are expected to exponentially increase. Elderly patients with hip fractures are at risk of complications, mortality and functional decline. Medical cost is another aspect as hip fracture treatment is relatively expensive [2]. This injury contributes only $14 \%$ of bone fractures but accounts for $72 \%$ of fracture-care expenses in geriatric patients [3]. Among predictors of poor prognosis and increased costs for hip fractures, waiting time to surgery (WTS) and hospital length of stay (LOS) have been identified as important factors. Patient-related factors or medical services both have potential impacts on the duration of WTS/LOS but their significance can vary across countries, regions, and hospitals [4]. Recognition of these factors and their influence on WTS and LOS is needed to optimize the care of these patients.

Vietnam is a developing country with an ageing population [5]. The ageing trend in Vietnam is predicted to deepen with more than one-quarter of the total population aged over 60 years old by 2049 [5]. Along with the increasing number of elderly persons, cases of hip fractures are expected to sharply increase. However, little is known about this type of injury in Vietnam. Our study aims to understand the clinical, laboratory findings and to identify pre-operative variables associated with increased WTS and LOS among hip fracture patients.

\section{METHODS}

This study is part of the thesis work for the degree of Doctor of Philosophy in Health Studies at the National Institute of Malaria, Parasitology and Entomology (NIMPE) of Vietnam. The research was approved on February 24, 2020, by the NIMPE review board (182/QD-VSR). Written informed consent was obtained from patients or their legal representatives for participation in the study. The anonymity of the subjects and the privacy of information were ensured as patient data was only reviewed by the research team and kept under strict confidentiality.

The prospective survey was conducted in Nghe at an Orthopaedic \& Trauma Hospital, Vietnam, between April 2020 and April 2021. All patients with undisplaced fractures of the proximal end of the femur and who agreed to participate in this prospective study were enrolled. Exclusion criteria were patients with multisystem trauma. Once patients were selected, relevant data

(C) Nguyen Nam H., Nguyen Le H., Vu Khoa V., Duong Chinh D., Cao Loi B., Le Anh T., 2021 
outcomes were extracted from their medical records using a standardised case report form. The demographic variables included gender, age, body mass index (BMI). Clinical variables included medical history, comorbidity, type of surgery (internal fixation or hip arthroplasty (HA), waiting time from the admission to surgery (WTS), and length of hospital stay (LOS). Following the standard protocol at the institution, all patients had completed pretreatment evaluation including standard tests of blood biochemistry and cell counts, and imaging analysis. Computed tomography (CT) scanning was used to evaluate the trauma and propose treatment decisions. The bone mineral density (BMD) of the femoral neck of the contralateral hip was determined by a dual-energy X-ray absorptiometry (Hologic Inc., USA) and expressed as T-score.

\section{Definition}

Anaemia at admission is defined as a haemoglobin level lower than $7.5 \mathrm{mmol} / \mathrm{L}[12 \mathrm{~g} / \mathrm{dL}]$ in women and $8.1 \mathrm{mmol} / \mathrm{L}[13 \mathrm{~g} / \mathrm{dL}]$ in men [6]. Patients with random plasma glucose $\geq 200 \mathrm{mg} / \mathrm{dL}(11.1 \mathrm{mmol} / \mathrm{L})$ or fasting plasma glucose $\geq 126 \mathrm{mg} / \mathrm{dL}(7.0 \mathrm{mmol} / \mathrm{L})$ were considered to have hyperglycemia [7]. Systolic blood pressure $(\mathrm{BP}) \geq 140 \mathrm{~mm} \mathrm{Hg}$ and/or diastolic $\mathrm{BP} \geq 90 \mathrm{~mm}$ was identified as elevated BP [8]. Body mass index (BMI, $\mathrm{Kg} / \mathrm{m}^{2}$ ) was categorized based on Asian criteria as follows: underweight $(<18.5)$, normal weight (18.5-23), overweight (23-27.5), and obesity $(\geq 27.5)$ [9]. The reference ranges of laboratory parameters were as follows: sodium 135-145 mmol/L, potassium 3.6-5.0 $\mathrm{mmol} / \mathrm{L}$, chloride $95-107 \mathrm{mmol} / \mathrm{L}$, calcium (total) $2.1-2.6 \mathrm{mmol} / \mathrm{L}$, urea $2.5-6.6 \mathrm{mmol} / \mathrm{L}$, creatinine $60-120 \mu \mathrm{mol} / \mathrm{L}$ [10]. The normal range for protein level is 6 to $8 \mathrm{~g} / \mathrm{dl}$ and albumin level is 3.5 to $5.0 \mathrm{~g} / \mathrm{dl}$ [10]. The C-reactive protein (CRP) levels were categorized as follows: less than or equivalent to $10.0 \mathrm{mg} / \mathrm{dL}$ : normal or moderate elevation; more than $10.0 \mathrm{mg} / \mathrm{dL}$ : marked elevation [11]. The T-score values were categorized based on World Health Organization criteria as follows: normal (-1.0 or greater), low bone mass (osteopenia) (between -1 to $-2.5 \mathrm{SD}$ ), or osteoporosis (-2.5 and lower) [12]. "Early operation" was defined as surgery undertaken within 48 hours of presenting to the hospital, and "delayed operation" as surgery done after 48 hours [13]. The median value was used as the cut point for LOS.

\section{Statistical Analysis}

Statistical analyses were performed using SPSS version 16.0. Continuous variables were expressed as means and standard deviations (SD) while categorical covariates were reported by frequencies and percentages. For univariate analysis, Pearson's chi-square tests and, when appropriate, Fisher exact tests were used for categorical variables. For continuous variables, the Student t-tests or Pearson correlations were applied for those with or without the predefined cut points. A multivariable linear regression model was used to analyze the effect of independent variables that had a potential association (e.g., $p<0.1$ ) on a binary outcome of WTS or LOS. Categorical variables were created from WTS and LOS to be used in the multivariate analysis. Significance was set at $\mathrm{P}<0.05$.

\section{RESULTS}

There were 118 patients aged between 61 and 101 years (mean, 79.5 years) included in the study. Most of them were only doing housework and no one was economically active. Overall, $66.9 \%$ of the patients had at least one comorbidity and $34 . \%$ of the patients had two or more comorbidities. Hypertension (50.8\%) and diabetes mellitus (DM; $40.7 \%$ ) were the most frequent comorbidities. The other comorbidities included coronary artery disease $(10.2 \%)$, pulmonary disease $(7.6 \%)$, gastrointestinal disease $(4.2 \%)$, neurologic disorders $(2.5 \%)$. Almost all $(95.8 \%)$ patients had fractures due to a low-impact fall. The intertrochanteric fracture was the predominant type of injury $(61.9 \%)$. Three out of 118 $(2.5 \%)$ patients insisted on discharge without treatment. The most frequent surgical operations were short stem partial HA (51.7 \%) and internal fixation (30.5\%).

The majority of patients were female $(68.6 \%)$ and the female to male ratio was 2.2. Compared to females, males were at a lower age $(p=0.048)$, had a higher value of BMI $(p=0.001)$, and a lower rate of DM $(p=0.05)$. Males were more likely to suffer from a fracture due to highenergy mechanisms $(p=0.033)$, femoral neck fracture $(p=0.043)$, and have fixation while females usually had fractures caused by a low-energy fall and underwent partial HA. All other findings were not significantly different between men and women (Table 1).

The laboratory data are presented in Table 2 . The most abnormal findings at admission were elevated C-reactive protein (CRP) levels, followed by decreased mineral density, anaemia, and hypoalbuminemia. Among 82 $(69.5 \%)$ patients with one or more types of electrolyte disorders, the most common imbalance was decreased sodium levels. Compared to males, females had lower haemoglobin levels but the prevalence of anaemia was similar between the two genders. Bone density was profoundly lower in females compared to males, and osteoporosis was 2.4 times more common in women than in men. The other laboratory findings were nearly comparable in both genders.

The mean and median of WTS were 52.1 and 47 hours, respectively. The interquartile range was 43 (hours). Of the 115 treated patients, 62 (53.9\%) had an early operation. Upon univariable analysis, only chloride elevation and type of surgery had a potential association with WTS $(\mathrm{p}<0.01)$. No association between WTS and these potential factors was found on multivariable analysis (Table 3 ).

Length of hospital stays varied from 5 to 35 days with a median time of 16 days. Results of the univariate analysis show that hypertension, hypoproteinemia, elevation of CRP, type of surgery, and WTS were significantly correlated with increased LOS. Among other parameters, hypoalbuminemia was potentially associated with extended LOS. Other clinical conditions and laboratory abnormalities were not related to a prolonged hospital stay $(\mathrm{p}$ values $>0.05)$ (Table 4$)$. 
Demographic and clinical characteristics of the study population $(\mathrm{N}=118)$

\begin{tabular}{|c|c|c|c|c|}
\hline \multirow{2}{*}{ Parameter } & \multirow{2}{*}{ Total } & \multicolumn{2}{|c|}{ Value $(\mathrm{N}, \%, \mathrm{CI} 95 \%$ or mean $\pm \mathrm{SD})$} & \multirow[b]{2}{*}{$p$} \\
\hline & & Male & Female & \\
\hline $\mathrm{N}$ & 118 & $37(31.4,21.9-40.1)$ & $81(68.6,57.7-79.5)$ & \\
\hline Age (years) & $79.5 \pm 9.4$ & $76.9 \pm 11.0$ & $80.6 \pm 8.4$ & $0.048^{*}$ \\
\hline BMI & $19.6 \pm 1.8$ & $20.4 \pm 2.0$ & $19.3 \pm 1.5$ & $0.001^{*}$ \\
\hline Underweight & $31(26.3,17.3-35.3)$ & $8(21.6,5.5-37.7))$ & $23(28.4,(17.5-39.3)$ & 0.051 \\
\hline Normal weight & $82(69.5,60.5-78.5)$ & $25(67.6,51.5-83.7)$ & $57(70.4,59.5-81.3)$ & \\
\hline Overweight and obese & $5(4.2)$ & $4(10.8)$ & $1(1.2)$ & \\
\hline \multicolumn{5}{|l|}{ Comorbidity } \\
\hline Hypertension & $60(50.8)$ & $20(54.1,37.9-70.2)$ & $40(49.4,38.5-60.3)$ & 0.694 \\
\hline Diabetes mellitus & $48(40.7)$ & $8(21.6,5.5-37.7)$ & $40(49.4,38.5-60.3)$ & $0.005^{*}$ \\
\hline \multicolumn{5}{|l|}{ Cause of fracture } \\
\hline Fall & $113(95.8,86.8-104.8)$ & $33(89.2)$ & $80(98.8)$ & $0.033^{*}$ \\
\hline Traffic accident & $5(4.2)$ & $4(10.8)$ & $1(1.2)$ & \\
\hline \multicolumn{5}{|l|}{ Type of fracture } \\
\hline Femoral neck fracture & $45(38.1,29.1-47.1)$ & $28(75.7)$ & $45(55.6)$ & 0.043 \\
\hline Intertrochanteric fracture & $73(61.9,52.9-70.9)$ & $9(24.3)$ & $36(44.4)$ & \\
\hline WTS (hours) & $52.1 \pm 33.9$ & $54.2 \pm 37.7$ & $49.7 \pm 29.6$ & 0.498 \\
\hline \multicolumn{5}{|l|}{ Type of treatment ${ }^{\dagger}$} \\
\hline None & $3(2.5)$ & $3(0)$ & $0(0)$ & \\
\hline Fixation & $36(30.5,21.5-39.5)$ & $15(40.5,24.4-56.6)$ & $21(25.9,15.0-36.8)$ & $0.036^{*}$ \\
\hline Partial HA & $79(67.0,57.9-76.0)$ & $19(51.3,35.2-67.4)$ & $60(74.1,56.5-78.2)$ & \\
\hline \multicolumn{5}{|l|}{ Complication $^{\dagger}$} \\
\hline Local infection & $3(2.6)$ & $2(5.4)$ & $1(1.2)$ & \\
\hline Systemic infection & $0(0)$ & & & \\
\hline In-hospital mortality & $0(0)$ & & & \\
\hline Length of stay ${ }^{\dagger}$ & $16(4.5)$ & $15.9 \pm 5.5$ & $15.9 \pm 4.3$ & 0.992 \\
\hline
\end{tabular}

Notes: ${ }^{*}$ - significant at $\mathrm{p}<0.05 ;{ }^{\dagger}-$ analysis of only 115 patients treated (34 men and 81 women)

Table 2

Laboratory findings at admission

\begin{tabular}{|c|c|c|c|c|}
\hline \multirow{2}{*}{ Parameter } & \multirow{2}{*}{ Total (118) } & \multicolumn{2}{|c|}{ Value $(\mathrm{N}, \%, \mathrm{CI} 95 \%$ or mean $\pm \mathrm{SD})$} & \multirow[b]{2}{*}{$p$} \\
\hline & & Male (37) & Female (81) & \\
\hline Hemoglobin $(\mathrm{g} / \mathrm{dL})$ & $108.1 \pm 15.6$ & $112.4 \pm 18.6$ & $106.1 \pm 13.6$ & $0.042^{*}$ \\
\hline Anemia & $96(81.4,72.4-90.4)$ & $29(78.4,62.3-94.5)$ & $67(82.7,71.8-93.5)$ & 0.615 \\
\hline Protein $(\mathrm{g} / \mathrm{dL})$ & $63.3 \pm 10.5$ & $63.1 \pm 11.9$ & $63.4 \pm 9.8$ & 0.866 \\
\hline Low protein & $24(20.3,11.3-29.3)$ & $8(21.6,5.5-37.7)$ & $6(19.8,8.9-30.7)$ & 0.810 \\
\hline Albumin $(\mathrm{g} / \mathrm{dL})$ & $33.2 \pm 4.4$ & $34.0 \pm 4.9$ & $32.8 \pm 4.1$ & 0.153 \\
\hline Low albumin & $78(66.1,57.1-75.1)$ & $21(56.8,40.7-72.9)$ & $57(70.4)$ & 0.208 \\
\hline T-score & $-2.0 \pm 1.3$ & $-1.5 \pm 1.3$ & $-2.3 \pm 1.2$ & $0.002^{*}$ \\
\hline \multicolumn{5}{|l|}{ Bone mineral density } \\
\hline Normal & $20(16.9,7.9-25.9)$ & $10(27.0,10.9-43.1)$ & $10(12.3,1.41-23.2)$ & $0.012^{*}$ \\
\hline Osteopenic & $54(45.8,36.8-54.8)$ & $20(54.1,37.9-70.2)$ & $34(42.0,31.1-52.9)$ & 0.306 \\
\hline Osteoporotic & $44(37.3,28.3-46.3)$ & $7(18.9,2.8-35.0)$ & $37(45.7,34.8-56.6)$ & 0.009 \\
\hline CRP value (mg/dL) & $71.2 \pm 63.2$ & $63.3 \pm 72.2$ & $74.8 \pm 58.8$ & 0.361 \\
\hline \multicolumn{5}{|l|}{ CRP level } \\
\hline Normal and moderate elevation & $35(29.7,20.7-38.7)$ & $14(37.8,21.7-53.9)$ & $21(25.9,15.0-36.7)$ & 0.272 \\
\hline Marked elevation & $83(70.3,61.3-79.3)$ & $23(62.2,46.1-78.3)$ & $60(74.1,63.2-84.9)$ & \\
\hline Ure $(\mathrm{mmol} / \mathrm{L})$ & $6.6 \pm 2.9$ & $6.7 \pm 2.6$ & $6.6 \pm 2.9$ & 0.881 \\
\hline Elevated ure & $39(33.1,24.1-42.1)$ & $15(40.5,24.4-56.6)$ & $24(29.6,18.7-40.5)$ & 0.293 \\
\hline Creatinin $(\mu \mathrm{mol} / \mathrm{L})$ & $64.8 \pm 12.3$ & $67.4 \pm 10.7$ & $63.6 \pm 12.9$ & 0.119 \\
\hline Elevated creatinin & $1(0.8)$ & & & \\
\hline Sodium $(\mathrm{mmol} / \mathrm{L})$ & 134.1 & $134.4 \pm 5.2$ & $133.9 \pm 4.7$ & 0.582 \\
\hline Decreased sodium level & $57(48.3,39.3-57.3)$ & $21(56.8,40.7-72.9)$ & $40(49.4,38.5-60.3)$ & 0.552 \\
\hline Calcium $(\mathrm{mmol} / \mathrm{L})$ & $2.2 \pm 0.2$ & $2.2 \pm 0.1$ & $2.1 \pm 0.2$ & 0.088 \\
\hline Decreased calcium level & $32(27.1,18.1-36.1)$ & $7(18.9,2.8-35.0)$ & $25(30.9,20.0-41.8)$ & 0.264 \\
\hline Sodium $(\mathrm{mmol} / \mathrm{L})$ & $3.8 \pm 0.7$ & $3.8 \pm 0.3$ & $3.9 \pm 0.8$ & 0.283 \\
\hline Decreased potassium level & $22(18.6,9.6-27.6)$ & $11(29.7,13.6-45.8)$ & $11(13.6,2.7-24.5)$ & 0.095 \\
\hline Chloride $(\mathrm{mmol} / \mathrm{L})$ & $111.4 \pm 83.4$ & $127.7 \pm 148.9$ & $103.9 \pm 3.5$ & 0.153 \\
\hline Elevated chloride level & $18(15.3,6.3-24.3)$ & $4(10.8,3.3-26.9)$ & $14(17.3,6.4-28.2)$ & 0.422 \\
\hline Abnormal electrolytes & $82(69.5,60.5-78.5)$ & $25(67.6,51.5-83.7)$ & $57(70.4,59.5-81.3)$ & 0.830 \\
\hline
\end{tabular}

Note: ${ }^{*}$ - significant at $\mathrm{p}<0.05$ 
Waiting time until surgery and related factors $(\mathrm{n}=115)$

\begin{tabular}{|c|c|c|c|c|c|}
\hline & \multicolumn{4}{|c|}{ Waiting time for operation (hours) (Mean $\pm \mathrm{SD}$ ) } & \multirow{2}{*}{$\begin{array}{c}p \\
0.498\end{array}$} \\
\hline Gender & Male $(\mathrm{n}=34)$ & $54.2 \pm 37.7$ & Female $(\mathrm{n}=81)$ & $49.7 \pm 29.6$ & \\
\hline Age (years)* & \multicolumn{4}{|c|}{0.031} & 0.740 \\
\hline BMI & Normal + overweight $(n=84)$ & $49.1 \pm 32.2$ & Underweight $(\mathrm{n}=31)$ & $60.2 \pm 37.5$ & 0.120 \\
\hline Hypertension & No $(\mathrm{n}=55)$ & $50.4 \pm 31.5$ & Yes $(n=60)$ & $51.7 \pm 32.9$ & 0.831 \\
\hline T-score & $>-2.5(n=73)$ & $53.5 \pm 35.6$ & $\leq-2.5(n=42)$ & $49.7 \pm 30.1$ & 0.566 \\
\hline Hypoproteinemia & No $(n=91)$ & $49.2 \pm 29.6$ & Yes $(n=24)$ & $58.0 \pm 40.0$ & 0.233 \\
\hline Hypoalbuminemia & No $(n=38)$ & $48.3 \pm 28.1$ & Yes $(n=77)$ & $52.4 \pm 34.1$ & 0.528 \\
\hline Anaemia & No $(n=22)$ & $41.4 \pm 22.5$ & Yes $(n=93)$ & $53.3 \pm 33.7$ & 0.116 \\
\hline Diabete mellitus & No $(n=68)$ & $52.4 \pm 35.2$ & Yes $(n=47)$ & $49.1 \pm 27.3$ & 0.583 \\
\hline CRP & Normal - elevation $(n=34)$ & $52.9 \pm 35.9$ & Marked elevation $(n=81)$ & $48.6 \pm 30.3$ & 0.209 \\
\hline Hyponatremia & No $(n=58)$ & $47.5 \pm 28.9$ & Yes $(n=57)$ & $54.7 \pm 35.0$ & 0.229 \\
\hline Hypokalemia & No $(n=93)$ & $53.2 \pm 36.7$ & Yes $(n=21)$ & $41.4 \pm 23.5$ & 0.129 \\
\hline Hypocalcemia & No $(n=84)$ & $53.6 \pm 33.1$ & Yes $(n=31)$ & $44.2 \pm 28.9$ & 0.167 \\
\hline Elevated chloride & No $(n=97)$ & $49.5 \pm 32.4$ & Yes $(n=18)$ & $66.2 \pm 39.0$ & 0.054 \\
\hline Elevated urea & No $(n=78)$ & $48.8 \pm 29.4$ & Yes $(n=37)$ & $55.7 \pm 37.3$ & 0.287 \\
\hline Type of fracture & Femoral neck $(n=42)$ & $49.3 \pm 27.8$ & Intertrochanteric $(\mathrm{n}=73)$ & $52.1 \pm 34.5$ & 0.661 \\
\hline Type of surgery & Fixation $(n=25)$ & $41.9 \pm 22.8$ & $\mathrm{HA}(\mathrm{n}=79)$ & $54.7 \pm 34.8$ & $0.089^{\dagger}$ \\
\hline
\end{tabular}

Notes: ${ }^{*}-$ Pearson correlation analysis; ${ }^{\dagger}-$ potential association

Table 4

Length of hospital stay with the other variables $(\mathrm{N}=115)$

\begin{tabular}{|c|c|c|c|c|c|}
\hline & \multicolumn{4}{|c|}{ Length of hospital stay (days) (Mean \pm SD) } & \multirow{2}{*}{$\begin{array}{c}\mathrm{p} \\
0.992\end{array}$} \\
\hline Gender & Male $(n=34)$ & $15.9 \pm 5.5$ & Female $(n=81)$ & $15.9 \pm 4.3$ & \\
\hline Age (years)* & \multicolumn{4}{|c|}{-0.56} & 0.549 \\
\hline BMI class & Normal + overweight $(n=84)$ & $16.1 \pm 4.8$ & Underweight $(\mathrm{n}=31)$ & $15.5 \pm 4.5$ & 0.581 \\
\hline Comorbidity & No $(n=38)$ & $16.6 \pm 5.9$ & Yes $(n=77)$ & $15.6 \pm 3.9$ & 0.312 \\
\hline Hypertension & No $(n=55)$ & $14.9 \pm 4.3$ & Yes $(n=60)$ & $16.9 \pm 4.9$ & $0.022^{\dagger}$ \\
\hline T-score & $>-2.5(n=73)$ & $16.3 \pm 4.7$ & $\leq-2.5(n=42)$ & $15.3 \pm 4.7$ & 0.288 \\
\hline Hypoproteinemia & No $(n=91)$ & $15.4 \pm 4.3$ & Yes $(n=24)$ & $17.9 \pm 5.6$ & $0.017^{\dagger}$ \\
\hline Hypoalbuminemia & No $(n=38)$ & $14.9 \pm 3.7$ & Yes $(n=77)$ & $16.5 \pm 5.0$ & $0.082^{\dagger}$ \\
\hline Anaemia & No $(n=22)$ & $15.9 \pm 3.0$ & Yes $(n=93)$ & $15.9 \pm 5.0$ & 0.966 \\
\hline Diabete mellitus & No $(n=68)$ & $16.4 \pm 4.5$ & Yes $(n=47)$ & $15.3 \pm 4.9$ & 0.233 \\
\hline CRP & Moderate elevation $(n=34)$ & $14.5 \pm 3.9$ & Marked elevation $(\mathrm{n}=81)$ & $16.6 \pm 4.8$ & $0.031^{\dagger}$ \\
\hline Hyponatremia & No $(n=58)$ & $15.8 \pm 4.2$ & Yes $(n=57)$ & $17.1 \pm 4.9$ & 0.129 \\
\hline Hypokalemia & No $(n=93)$ & $16.1 \pm 4.9$ & Yes $(n=21)$ & $15.2 \pm 3.5$ & 0.452 \\
\hline Hypocalcemia & No $(n=84)$ & $15.5 \pm 4.9$ & Yes $(n=31)$ & $14.5 \pm 3.5$ & 0.141 \\
\hline Elevated chloride & No $(n=97)$ & $15.7 \pm 4.8$ & Yes $(n=18)$ & $66.2 \pm 39.1$ & 0.156 \\
\hline Elevated urea & No $(n=78)$ & $15.6 \pm 4.6$ & Yes $(n=37)$ & $16.7 \pm 4.8$ & 0.253 \\
\hline Type of fracture & Femoral neck $(n=42)$ & $16.1 \pm 4.1$ & Intertrochanteric $(\mathrm{n}=73)$ & $15.9 \pm 5.0$ & 0.831 \\
\hline Type of surgery & Fixation $(n=36)$ & $13.7 \pm 3.7$ & $\mathrm{HA}(\mathrm{n}=79)$ & $16.9 \pm 4.8$ & $0.000^{\dagger}$ \\
\hline WTS & Early $(n=62)$ & $14.8 \pm 4.3$ & Delayed $(n=53)$ & $17.3 \pm 4.9$ & $0.004^{\dagger}$ \\
\hline
\end{tabular}

Notes: * - Pearson correlation analysis; ${ }^{\dagger}-$ potential or significant association

Table 5

Multivariate analysis of factors associated with $\operatorname{LOS}(\mathrm{N}=115)$

\begin{tabular}{|l|c|c|c|}
\hline \multicolumn{1}{|c|}{ Parameter } & OR & CI 95\% & p \\
\hline Hypertension & 1.476 & $0.634 \pm 3.438$ & 0.367 \\
\hline Hypoproteinemia & 1.411 & $0.482 \pm 4.133$ & \\
\hline Hypoalbuminemia & 0.784 & $0.258 \pm 2.377$ & \\
\hline Marked elevated CRP & 3.317 & $1.045 \pm 10.531$ & 0.530 \\
\hline Type of surgery & 4.413 & $1.575 \pm 12.366$ & \\
\hline WTS & 4.602 & $1.897 \pm 11.166$ & 0.042 \\
\hline
\end{tabular}

For multivariate analysis, patients with a LOS smaller than 16 days were grouped (short LOS) to compare with those who stayed for 16 days or longer (long LOS). Results in Table 5 demonstrate that marked elevation of CRP level, type of surgery and time of admission to surgery are independent variables affecting LOS. The effect of potential factors such as hypertension, hypoproteinemia, hypoalbuminemia on LOS does not reach significance $(\mathrm{p}>0.05)$.

\section{DISCUSSION}

Clinical and laboratory findings

The first aim of this study was to find out the clinical and laboratory characteristics of Vietnamese patients with a hip fracture, a common and painful injury. The results show that the clinical characteristics in our sample did not differ much from what was found in previous 
studies. The common occurrence of hip fracture in the elderly, and mainly in the women in this study, is a typical characteristic of the injury $[1,14]$. Given the characteristics of studied patients, the very high rate of comorbidities in this study (66.9\% of the participants) is expected and has been observed elsewhere [15]. In agreement with other reports, the most common cause of fracture was a fall (95\% of the patients) and only $5 \%$ of participants had an injury after an accident [14]. The predominant type of intertrochanteric fracture in this study is similar to those observed in other studies [16]. Compared to femoral neck fractures, a break in the intertrochanteric region is associated with a poorer prognosis [17]. The difference between females and males in terms of BMI, bone density, or rate of DM are in line with other observations in Vietnam and other countries $[18,19]$. A traffic accident was more likely the cause of hip fractures in males compared to women which were similar to trends noted in developing countries [20]. The only notable exception in our study was that the prevalence of overweight was low $(4.2 \%)$ compared to reports in developed countries (about $20 \%$ ) [21]. It is difficult to assess the association between this difference and the prognosis of hip fracture because findings on the relationship between obesity and bone fracture are inconsistent. Some studies found the protective effect of obesity against fracture [22] while others show that a higher body mass is a significant risk factor for fracture [23]. The average time to surgical treatment after admission in our study (52.1 hours) is longer than the findings in some other countries such as Taiwan (29.2 hours) [24], Sweden (median 20 hours) [25]. Although the optimal length of WTS has not been defined, waiting for more than 48 hours from admission to undergo an operation is considered "delayed" and is associated with worse outcomes of patients [26]. The mean LOS of the patients undergoing surgical treatment in our patients (15 days) is higher compared to reports in some other countries (ranging from 6.5 to 11.6 days) [27, 28]. These results suggest that necessary measures to shorten WTS and LOS are needed to reduce mortality risk and medical care costs of hip fracture patients in Vietnam [2, 28].

Concerning the laboratory results, our findings show a high prevalence of low BMD, anaemia, increased CRP level, low albumin concentration, and electrolyte disorders among patients with hip fractures. The high prevalence of decreased BMD $(83.1 \%)$ was compatible with the high rate of hip fracture due to low-impact falls. A very high rate of anaemia in our patients $(81.4 \%)$ has been noted in other studies as a normal consequence of hip fractures due to bone vascularity [29]. Elevated CRP was reported in almost all $(94.9 \%)$ patients which is similar to other observations [30]. The frequency of other abnormalities such as hypoproteinemia, hypoalbuminemia, raised urea concentration and electrolyte imbalance has been reported in the literature $[31,32,33,34]$.

Predictors of the time from admission to surgery and LOS

The second aim of this study is to figure out determinants of WTS and LOS in patients with hip fractures. Among clinical or laboratory findings we did not find any single patient-related factor that was significantly associated with increased WTS. In general, WTS depends on both patient and system factors [35]. The list of patients' reasons for delayed operation is very extensive and includes age, gender, socioeconomic status, injury, comorbidity, examination and treatment before surgery, and, sometimes, personal reasons [35]. However, the influence of these factors on the likelihood of surgical delay are diverse and may be conflicting. For example, Ryan DJ et al. (2015) reported that age could affect WTS [13] but in Ricci WM et al. (2015), age was not associated with increased WTS [36]. These conflicting results are explainable given that most patients with hip fractures are elderly and have multiple underlying comorbidities and medical disorders. Therefore, it is difficult to find an independent factor that significantly influences WTS among patients who have such a variety of medical problems.

In examining the relationship between pre-operative findings with LOS, our data showed that marked elevation of CRP level, type of surgery and delayed operation were independently associated with increased LOS. Similar to WTS, LOS is governed by several factors including patient-related and system-related ones and the literature assessing predicting factors of greater LOS remains heterogeneous and conflicting. Some observations have found the relationship between patient-related factors such as age [36, 37, 38], gender [4, 38], comorbidities [4, 37, 38], the cause [38] or type of fracture $[37,38]$ and prolonged LOS. Some other observations found no association between age [16, 39], gender [37], comorbidities, [37], type of fracture [39] with extended LOS as in our study. The relationship between CRP level and LOS could be anticipated but rarely reported in the literature. Elevated CRP is related to a higher rate of bone loss [40] which is often associated with hip fractures in the elderly [41]. In addition, the elevation of CRP is related to a high level of tissue damage [42] and increased risk of complications after the trauma [30] which has a significant impact on outcomes of hip fracture patients. The effect of type of surgery and WTS on LOS found in our study has been corroborated in previous observations [13, 37, 43, 44]. Our results on predictors of LOS would have great practical implications. While some predictors such as the elevation of CRP are dependent on patients' condition [45] and consistent across sites, the type of surgery and WTS may be hospital specific and modifiable by improving the availability of medical resources or patient flow [35].

Despite the limitations of being a single-centre study, we believe our results provide a useful understanding of independent factors affecting the WTS and LOS in patients with hip fractures. The setting in this study is an orthopaedic hospital of the provincial level which offers services similar to many level II centres throughout the world. Our study population is similar in demographic and clinical characteristics to hip fracture patients worldwide. These similarities indicate that independent factors affecting the length of stay found in our study could be applicable to hip fractures in other level II centres. 


\section{CONCLUSION}

Our research has shown that patients having hip fractures in Vietnam share many common characteristics with those in other countries except for the high number of underweight patients. Given that most patients are elderly and suffer from many comorbidities and laboratory abnormalities, appropriate assessment and correction of medical problems are vital to preoperative preparation for those patients. The significant association between type of surgery and waiting time to operation with the length of hospital stay has great practical implications to improving patient satisfaction, as well as decreasing the burden on health staff.

\section{REFERENCES}

1. Veronese N., Maggi S. Epidemiology and social costs of hip fracture. Injury, 2018, vol. 49, no. 8, pp. 1458-1460. DOI: 10.1016/j.injury.2018.04.015.

2. Youm T., Koval K.J., Zuckerman J.D. The economic impact of geriatric hip fractures. Am. J. Orthop. (Belle Mead NJ), 1999, vol. 28, no. 7, pp. 423-428.

3. Burge R., Dawson-Hughes B., Solomon D.H., Wong J.B., King A., Tosteson A. Incidence and economic burden of osteoporosis-related fractures in the United States, 2005-2025. J. Bone Miner. Res., 2007, vol. 22, no. 3, pp. 465-475. DOI: 10.1359/jbmr.061113.

4. Knoll O.M., Lakomkin N., Shen M.S., Adebayo M., Kothari P., Dodd A.C., Attum B., Lee N., Chona D., Sethi M.K. A predictive model for increased hospital length of stay following geriatric hip fracture. J. Clin. Orthop. Trauma, 2019, vol. 10, no. Suppl. 1, pp. S84-S87. DOI: 10.1016/j.jcot.2019.03.024.

5. Handong L., Hongngoc N., Tianmin Z. Vietnam's Population Projections and Aging Trends from 2010 to 2049. J. Population Ageing, 2021, vol. 14, no. 6, pp. 165-182. DOI: 10.1007/s12062-019-09257-3.

6. WHO. Haemoglobin Concentrations for the Diagnosis of Anaemia and Assessment of Severity. World Health Organization. Geneva, 2011. Available at: https://apps.who.int/iris/handle/10665/85839.

7. American Diabetes Association. 2. Classification and Diagnosis of Diabetes: Standards of Medical Care in Diabetes-2020. Diabetes Care, 2020, vol. 43, no. Suppl. 1, pp. S14-S31. DOI: 10.2337/dc20-S002.

8. WHO Noncommunicable diseases: Hypertension. World Health Organization. Geneva, September 29, 2015.

9. WHO Expert Consultation. Appropriate body-mass index for Asian populations and its implications for policy and intervention strategies. Lancet, 2004, vol. 363, no. 9403, pp. 157-163. DOI: 10.1016/S0140-6736(03)15268-3.

10. Ralston S., Penman I., Strachan M., Hobson R., editors. Davidson’s Principles and Practice of Medicine. 23d Ed. Elsevier. 2018. 1440 p.

11. Nehring S.M., Goyal A., Bansal P., Patel B.C. C Reactive Protein (CRP). Treasure Island, FL, StatPearls Publishing, 2020.

12. Lewiecki E.M. Osteoporosis: Clinical Evaluation. In: Feingold K.R., Anawalt B., Boyce A., Chrousos G., De Herder W.W., Dhatariya K., Dungan K., Hershman J.M., Hofland J., Kalra S., Kaltsas G., Koch C., Kopp P., Korbonits M., Kovacs C.S., Kuohung W., Laferrère B., Levy M., McGee E.A., McLachlan R., Morley J.E., New M., Purnell J., Sahay R., Singer F., Sperling M.A., Stratakis C.A., Trence D.L., Wilson D.P., editors. Endotext. South Dartmouth (MA), MDText.com, Inc. 2000. Available at: https://www.ncbi.nlm.nih.gov/books/NBK279049/

13. Ryan D.J., Yoshihara H., Yoneoka D., Egol K.A., Zuckerman J.D. Delay in Hip Fracture Surgery: An Analysis of Patient-Specific and Hospital-Specific Risk Factors. J. Orthop. Trauma, 2015, vol. 29, no. 8, pp. 343-348. DOI: 10.1097/BOT.0000000000000313.

14. Arshad A., Ibrahim M.T., Arshad H., Hammad M.B., Sheikh S.A., Khan A.H., Jafri L., Nadeem S. Clinical characteristics and outcomes of patients presenting with hip fractures at a tertiary care hospital in Pakistan. Arch. Osteoporos., 2021, vol. 16, no. 1, pp. 25. DOI: 10.1007/s11657-021-00895-9.

15. Tan S.T., Tan W.P., Jaipaul J., Chan S.P., Sathappan S.S. Clinical outcomes and hospital length of stay in 2,756 elderly patients with hip fractures: a comparison of surgical and non-surgical management. Singapore Med. J., 2017, vol. 58, no. 5, pp. 253-257. DOI: 10.11622/smedj.2016045.

16. Taylor M., Hopman W., Yach J. Length of stay, wait time to surgery and 30-day mortality for patients with hip fractures after the opening of a dedicated orthopedic weekend trauma room. Can. J. Surg., 2016, vol. 59, no. 5, pp. 337-341. DOI: 10.1503/cjs.017014.

17. Haentjens P., Autier P., Barette M., Venken K., Vanderschueren D., Boonen S.; Hip Fracture Study Group. Survival and functional outcome according to hip fracture type: a one-year prospective cohort study in elderly women with an intertrochanteric or femoral neck fracture. Bone, 2007, vol. 41, no. 6, pp. 958-964. DOI: 10.1016/j.bone.2007.08.026.

18. Tuan N.T., Tuong P.D., Popkin B.M. Body mass index (BMI) dynamics in Vietnam. Eur. J. Clin. Nutr., 2008, vol. 62, no. 1, pp. 78-86. DOI: 10.1038/ sj.ejcn.1602675.

19. Daly R.M., Rosengren B.E., Alwis G., Ahlborg H.G., Sernbo I., Karlsson M.K. Gender specific age-related changes in bone density, muscle strength and functional performance in the elderly: a-10 year prospective population-based study. BMC Geriatr., 2013, vol. 13, pp. 71. DOI: 10.1186/14712318-13-71.

20. George J., Sharma V., Farooque K., Mittal S., Trikha V., Malhotra R. Injury Mechanisms of Hip Fractures in India. Hip Pelvis, 2021, vol. 33, no. 2, pp. 62-70. DOI: $10.5371 / \mathrm{hp} .2021 .33 .2 .62$

21. Chan M.Y., Frost S.A., Center J.R., Eisman J.A., Nguyen T.V. Relationship between body mass index and fracture risk is mediated by bone mineral density. J. Bone Miner. Res., 2014, vol. 29, no. 11, pp. 2327-2335. DOI: 10.1002/jbmr.2288.

22. Johnell O., Gullberg B., Kanis J.A., Allander E., Elffors L., Dequeker J., Dilsen G., Gennari C., Lopes V.A., Lyritis G., Mazzuoli G., Miravet L., Passeri M., Cano P.R., Rapado A., Ribot C. Risk factors for hip fracture in European women: the MEDOS Study. Mediterranean Osteoporosis Study. J. Bone Miner. Res., 1995, vol. 10, no. 11, pp. 1802-1815. DOI: 10.1002/jbmr.5650101125.

23. Compston J.E., Watts N.B., Chapurlat R., Cooper C., Boonen S., Greenspan S., Pfeilschifter J., Silverman S., Dez-Pérez A., Lindsay R., Saag K.G., Netelenbos J.C., Gehlbach S., Hooven F.H., Flahive J., Adachi J.D., Rossini M., LaCroix A.Z., Roux C., Sambrook P.N., Siris E.S., Glow Investigators. Obesity is not protective against fracture in postmenopausal women: GLOW. Am. J. Med., 2011, vol. 124, no. 11, pp. 1043-1050. DOI: 10.1016/j. amimed.2011.06.013.

24. Shen C.Y., Hsiao C.H., Tsai W., Chang W.H., Chen T.H. Associations between Hip Fracture Operation Waiting Time and Complications in Asian Geriatric Patients: A Taiwan Medical Center Study. Int. J. Environ. Res. Public Health, 2021, vol. 18, no. 6, pp. 2848. DOI: 10.3390/ijerph18062848.

25. Greve K., Modig K., Talbäck M., Bartha E., Hedström M. No association between waiting time to surgery and mortality for healthier patients with hip fracture: a nationwide Swedish cohort of 59,675 patients. Acta Orthop., 2020, vol. 91, no. 4, pp. 396-400. DOI: 10.1080/17453674.2020.1754645.

26. Lewis P.M., Waddell J.P. When is the ideal time to operate on a patient with a fracture of the hip? : a review of the available literature. Bone Joint J., 2016, vol. 98-B, no. 12, pp. 1573-1581. DOI: 10.1302/0301-620X.98B12.BJJ-2016-0362.R2.

27. National Hospital Discharge Survey (NHDS). United States Department of Health and Human Services. National Center for Health Statistics. 1990. Available at: https://doi.org/10.3886/ICPSR06222.v1.

28. Nikkel L.E., Kates S.L., Schreck M., Maceroli M., Mahmood B., Elfar J.C. Length of hospital stay after hip fracture and risk of early mortality after discharge in New York state: retrospective cohort study. BMJ, 2015, vol. 351, pp. h6246. DOI: 10.1136/bmj.h6246.

29. Lieurance R., Benjamin J.B., Rappaport W.D. Blood loss and transfusion in patients with isolated femur fractures. J. Orthop. Trauma, 1992, vol. 6, no. 2, pp. 175-179. DOI: 10.1097/00005131-199206000-00007.

30. Fakler J.K., Grafe A., Dinger J., Josten C., Aust G. Perioperative risk factors in patients with a femoral neck fracture - influence of 25-hydroxyvitamin D and C-reactive protein on postoperative medical complications and 1-year mortality. BMC Musculoskelet. Disord., 2016, vol. 17, pp. 51. DOI: 10.1186/ s12891-016-0906-1.

31. Lewis J.R., Hassan S.K., Wenn R.T., Moran C.G. Mortality and serum urea and electrolytes on admission for hip fracture patients. Injury, 2006, vol. 37, no. 8, pp. 698-704. DOI: 10.1016/j.injury.2006.04.121. 
32. Laulund A.S., Lauritzen J.B., Duus B.R., Mosfeldt M., Jørgensen H.L. Routine blood tests as predictors of mortality in hip fracture patients. Injury, 2012, vol. 43, no. 7, pp. 1014-1020. DOI: 10.1016/j.injury.2011.12.008.

33. Bohl D.D., Shen M.R., Hannon C.P., Fillingham Y.A., Darrith B., Della Valle C.J. Serum Albumin Predicts Survival and Postoperative Course Following Surgery for Geriatric Hip Fracture. J. Bone Joint Surg. Am., 2017, vol. 99, no. 24, pp. 2110-2118. DOI: 10.2106/JBJS.16.01620.

34. Shi L.T., Cao X.Y., Gu R., Zhao J.X., Zhang Y. Incidence and clinical significance of abnormalities in potassium, sodium and calcium levels in elderly patients with hip fractures during the perioperative period. Ann. Ital. Chir., 2020, vol. 91, pp. 187-191.

35. Sheehan K.J., Sobolev B., Villán Villán Y.F., Guy P. Patient and system factors of time to surgery after hip fracture: a scoping review. BMJ Open, 2017, vol. 7, no. 8, pp. e016939. DOI: 10.1136/bmjopen-2017-016939.

36. Ricci W.M., Brandt A., McAndrew C., Gardner M.J. Factors affecting delay to surgery and length of stay for patients with hip fracture. J. Orthop. Trauma, 2015, vol. 29, no. 3, pp. e109-e114. DOI: 10.1097/BOT.0000000000000221.

37. Lefaivre K.A., Macadam S.A., Davidson D.J., Gandhi R., Chan H., Broekhuyse H.M. Length of stay, mortality, morbidity and delay to surgery in hip fractures. J. Bone Joint Surg. Br., 2009, vol. 91, no. 7, pp. 922-927. DOI: 10.1302/0301-620X.91B7.22446.

38. Castelli A., Daidone S., Jacobs R., Kasteridis P., Street A.D. The Determinants of Costs and Length of Stay for Hip Fracture Patients. PLoS One, 2015, vol. 10, no. 7, pp. e0133545. DOI: 10.1371/journal.pone.0133545.

39. Richards T., Glendenning A., Benson D., Alexander S., Thati S. The independent patient factors that affect length of stay following hip fractures. Ann. R. Coll. Surg. Engl., 2018, vol. 100, no. 7, pp. 556-562. DOI: 10.1308/rcsann.2018.0068.

40. Berglundh S., Malmgren L., Luthman H., McGuigan F., Åkesson K. C-reactive protein, bone loss, fracture, and mortality in elderly women: a longitudinal study in the OPRA cohort. Osteoporos. Int., 2015, vol. 26, no. 2, pp. 727-735. DOI: 10.1007/s00198-014-2951-7.

41. Cauley J.A., Barbour K.E., Harrison S.L., Cloonan Y.K., Danielson M.E., Ensrud K.E., Fink H.A., Orwoll E.S., Boudreau R. Inflammatory Markers and the Risk of Hip and Vertebral Fractures in Men: the Osteoporotic Fractures in Men (MrOS). J. Bone Miner. Res., 2016, vol. 31, no. 12, pp. $2129-2138$. DOI: $10.1002 / j b m r .2905$.

42. Neumaier M., Metak G., Scherer M.A. C-reactive protein as a parameter of surgical trauma: CRP response after different types of surgery in 349 hip fractures. Acta Orthop., 2006, vol. 77, no. 5, pp. 788-790. DOI: 10.1080/17453670610013006.

43. Paul P., Issac R.T. Delay in time from fracture to surgery: A potential risk factor for in-hospital mortality in elderly patients with hip fractures. J. Orthop., 2018, vol. 15, no. 2, pp. 375-378. DOI: 10.1016/j.jor.2018.03.001.

44. McIsaac D.I., Abdulla K., Yang H., Sundaresan S., Doering P., Vaswani S.G., Thavorn K., Forster A.J. Association of delay of urgent or emergency surgery with mortality and use of health care resources: a propensity score-matched observational cohort study. CMAJ, 2017, vol. 189, no. 27, pp. E905-E912. DOI: 10.1503/cmaj.160576.

45. Parker M., Johansen A. Hip fracture. BMJ, 2006, vol. 333, no. 7557, pp. 27-30. DOI: 10.1136/bmj.333.7557.27.

The article was submitted 08.07.2021; approved after reviewing 23.09.2021; accepted for publication 19.10.2021.

\section{Information about the authors:}

1. Nam Hoai Nguye-M.D., hoainam502@gmail.com;

2. Le Huu Nguyen - M.D., lebvmna@gmail.com;

3. VKhoa Van Vu - M.D., bskhoavd@gmail.com;

4. Chinh Dinh Duong - M.D., chinhuehoang@gmail.com;

5. Loi Ba Cao - M.D., Phucloikhdt@gmail.com;

6. Anh Tran Le-M.D., anh_1t@vmmu.edu.vn.

Conflict of interest The authors declare that there were no conflicts of interest in this study and agree to submit the manuscript for possible publication in «Genij Ortopedii».

Financial disclosure The authors received no financial support for the research, authorship, and/or publication of this article. 